\title{
Extensive hypovitaminosis D amongst Saudi Arabian adolescent females: age and gender comparisons
}

\author{
M. Al-Ghamdi ${ }^{1}$, S. Lanham-New ${ }^{2}$ and J. A. Khan ${ }^{1}$ \\ ${ }^{1}$ Joint Supervision Programme, Biochemistry Department, King Abdul Aziz University, PO Box 42612, Jeddah 21551, \\ Kingdom of Saudi Arabia and ${ }^{2}$ Faculty of Health and Medical Science, University of Surrey, Guildford GU2 7XH, UK
}

There is a growing concern of extensive hypovitaminosis D in female population groups living in the Middle East. Few data exist looking at vitamin D status in young boys and girls from Saudi Arabia. The aim of the present study therefore was to determine the extent of poor vitamin D status in schoolchildren (boys and girls, pre- and post-pubertal) and examine specifically if there was any difference in status with chronological age. This research forms part of on-going work on vitamin D and bone health at the King Abdul Aziz University in $\operatorname{Jeddah}^{(1)}$.

School-age children (6-18 years) were identified from a selection of schools in the city of Jeddah with assistance from the Ministry of Education. Three schools were used for the selection of boys and two schools for the selection of girls that represented areas of different socio-economic status. A total of 150 boys (age range 7-16 years) and 150 girls (age range 6-18 years) participated in the study. A fasted blood sample was collected for assessment of vitamin D (25OHD), parathyroid hormone (PTH), Ca and albumin. Weight and height was recorded and subjects were asked to complete a lifestyle questionnaire that asked about their physical activity levels and dietary habits. Data on bone mass and bone metabolism were also collected (but not reported here).

The mean age (years) of the boys and the girls was 11.2 (SD 2.4) v. 11.3 (SD 2.4) respectively. Vitamin D status was significantly higher in the boys (all age groups combined; 25OHD 54.9 (SD 13.7) nmol/l) than the girls (25OHD 32.7 (SD 10.7) nmol/l), with a concomitant higher PTH for the girls (7.7 (SD 5.6) pmol/l) $v$. the boys (5.5 (SD 3.2) pmol/l). The percentage of older girls ( $>12$ years) who had vitamin D levels $<25 \mathrm{nmol} / \mathrm{l}$ and $<50 \mathrm{nmol} / \mathrm{l}$ were $39 \%$ and $98 \%$ respectively whereas no boys and only $6 \%$ of younger girls were $<25 \mathrm{nmol} / \mathrm{l}$.

\begin{tabular}{|c|c|c|c|c|c|c|c|c|c|}
\hline & \multicolumn{4}{|c|}{ Boys } & \multicolumn{4}{|c|}{ Girls } & \multirow[b]{3}{*}{$P$} \\
\hline & \multicolumn{2}{|c|}{ Older } & \multicolumn{2}{|c|}{ Younger } & \multicolumn{2}{|c|}{ Older } & \multicolumn{2}{|c|}{ Younger } & \\
\hline & $\overline{\text { Mean }}$ & SD & Mean & SD & $\overline{\text { Mean }}$ & SD & Mean & SD & \\
\hline 25OHD (nmol/l) & $50.9^{\mathrm{a}}$ & 12.2 & $60.6^{\mathrm{b}}$ & 13.8 & $28.1^{\mathrm{c}}$ & 9.9 & $38.2^{\mathrm{d}}$ & 9.0 & 0.001 \\
\hline PTH $(\mathrm{pmol} / \mathrm{l})$ & $5.9^{\mathrm{a}}$ & 2.8 & $4.9^{\mathrm{b} * *}$ & 3.8 & $9.2^{\mathrm{b}}$ & 6.6 & $5.9^{\mathrm{b}}$ & 3.1 & 0.001 \\
\hline $\mathrm{Ca}(\mathrm{mmol} / \mathrm{l})$ & 2.30 & 0.07 & 2.30 & 0.08 & 2.32 & 0.08 & 2.29 & 0.09 & NS \\
\hline Albumin (g/l) & $44.7^{\mathrm{a}}$ & 8.1 & $43.9^{\mathrm{a}}$ & 3.2 & $46.1^{\mathrm{b}}$ & 5.7 & $45.1^{\mathrm{c}}$ & 6.2 & 0.01 \\
\hline Alkaline phosphatase (U/l) & $283^{\mathrm{a}}$ & 90.2 & $240^{\mathrm{b}}$ & 49.8 & $213^{\mathrm{a}}$ & 106 & $243^{\mathrm{c}}$ & 64.8 & 0.001 \\
\hline
\end{tabular}

$\overline{\mathrm{a}, \mathrm{b}, \mathrm{c}, \mathrm{d}}$ Values in rows with unlike superscript letters were significantly different (ANOVA and Kruskal Wallis; $P<0.05 ; * * P<0.001$ ).

As shown in the Table, when groups were examined by age, given that veiling in Saudi Arabian girls commences at puberty (mean age approximately 12 years), 25OHD was significantly lower for the older girls ( $>12$ years, $n 82 ; 28.1$ (SD 9.9) nmol/l than for their younger counterparts $(n$ 68; 38.2 (SD 9.0) nmol/1; $P<0.001$ ), with a parallel increase in PTH in the older girls when compared with the younger girls (9.2 (SD 6.6) pmol/l v. 5.9 (SD 3.1) pmol/l) and older boys (9.2 (SD 6.6) pmol/l v. 5.9 (SD 2.8) pmol/l) and a parallel increase in PTH in the older boys when compared with the younger boys (5.9 (SD 3.1) pmol/l) $v$. (4.9 (SD 3.8) pmol/l).

These data suggest significant hypovitaminosis D in older adolescent females. Further analysis is currently underway to examine the effects of poor vitamin D status on bone density (as measured by dual X-ray absorptiometry and broadband ultrasound attenuation) and markers of bone turnover. These data are a cause for concern given that low vitamin D status is adversely associated with a number of health outcomes and there is currently no public health policy for vitamin D in the Kingdom of Saudi Arabia.

Financial support from the King Abdul Aziz University is gratefully acknowledged.

1. Khoja SA, Khan J, Maimani ARA et al. (2007) Int Congr Ser 1297, 296-302. 